\title{
European Surveillance of Infections in Cancer Patients - ESIC
}

\author{
M. Karthaus ${ }^{a} \quad$ D. Buchheidt ${ }^{b} \quad$ W. Hiddemann ${ }^{c} \quad$ J.P. Donnelly ${ }^{d}$ \\ V. Krcmery ${ }^{\mathrm{e}}$ X. Schiel ${ }^{\mathrm{c}} \quad$ M. Wilhelm ${ }^{f}$ M. Helmerking ${ }^{g}$ \\ On behalf of the ESIC Study Group \\ aDepartment of Hematology and Oncology, Medical School, Hannover, \\ bIII. Medizinische Klinik, Klinikum Mannheim, cIII. Medizinische Klinik, \\ University Hospital Grosshadern, Munich, Germany, dUniversity Hospital St. Radboud, \\ Nijmegen, The Netherlands, eSt. Elisabeth Hospital, Bratislava, Slovak Republic, \\ fUniversity of Würzburg, Medizinische Poliklinik, Würzburg, \\ gEuropean Society of Biomodulation and Chemotherapy, Munich, Germany
}

\section{Key Words}

Febrile neutropenia $\cdot$ Risk factors for complications · Antimicrobial agents

\begin{abstract}
Major advances in cancer therapy result from development of multidrug chemotherapy regimens. Besides death from tumor progression, infections are currently one of the major causes of mortality and morbidity. Because of the risk of complications and mortality, the treatment for febrile neutropenia is admission to hospital and administration of broad-spectrum antibiotics. Response rates of initial antimicrobial treatment vary considerably (40-92\%). Due to the heterogeneity of populations in randomized studies, comparison of efficacy and identification of risk factors is limited. This is the main reason why
\end{abstract}

\begin{tabular}{ll}
\hline KARGER & (1999 S. Karger AG, Basel \\
Fax + 4161306 12 34 & 0009-3157/99/0454-0237\$17.50/0 \\
$\begin{array}{l}\text { E-Mail karger@karger.ch } \\
\text { www.karger.com }\end{array}$ & Accessible online at: \\
http://BioMedNet.com/karger
\end{tabular}

the European Society of Biomodulation and Chemotherapy (ESBiC) is conducting a surveillance study that concentrates more on the evaluation of risk factors than on the therapeutic outcome of prospective randomized antimicrobial regimens: European Surveillance of Infections in Cancer Patients (ESIC). The present contribution is to determine which cancer patients are at low risk for fever, and can benefit from first-line treatment with treatment options such as monotherapy as well as on an outpatient basis.

\section{Introduction}

The last two decades have seen major advances in cancer therapy. As a result of the development of multidrug chemotherapy reg-

\footnotetext{
Dr. Meinolf Karthaus

Hannover Medical School, Department of Hematology and Oncology Carl-Neuberg-Strasse 1

D-30625 Hannover (Germany)

Tel. +49511532 3013, Fax +495115323021
} 
imens, testicular and ovarian neoplasms, choriocarcinoma. Wilm's tumor, small-cell lung carcinoma, leukemia in children and adults, and malignant lymphoma have become potentially curable, even if the disease is advanced. Increasing attention is therefore being paid to the side effects of intensive chemotherapy. Besides death from tumor progression, infections are currently one of the major causes of mortality and morbidity. Because of the risk of complications and mortality, the treatment of febrile neutropenia is admission to hospital and administration of broad-spectrum antibiotics, usually a combination of a broad-spectrum $\beta$-lactam and an aminoglycoside [1].

Extensive research in management of infections in cancer patients has been conducted. Major research activities in Europe were carried out by the EORTC (European Organization for Research and Treatment of Cancer) [2], which has organized 13 international prospective studies since 1970. In addition, in Italy the GIMEMA (Gruppo Italiano Malattie Ematologiche Maligne dell'Adulto) study group conducted 7 studies and in Germany the PEG (Paul-Ehrlich-Gesellschaft) study group 3 studies [3, 4]. The response rates of prospective studies of antimicrobial treatment vary considerably (40-92\%), and the heterogeneity of the study populations limits comparisons of efficacy [1]. In addition, all studies were therapeutically oriented and compared two or more therapeutic regimens. In contrast to randomized antibiotic treatment protocols, only a small number of studies focused on the identification of risk factors, in particular of the Invasive Fungal Infection Co-operative Group of the EORTC, which were recently published $[5,6]$. However, these evaluations were limited to fungal infections only $[5,6]$.

It is generally recognized that the risk of morbidity and mortality is high following al- logeneic bone marrow transplantation and in prolonged aplasia resulting from induction treatment for acute leukemia. In contrast to these patients with a high risk feature in febrile episodes with neutropenia, certain studies have shown that alternatives such as outpatient treatment [7-11], or monotherapy may be safe as well as effective in febrile neutropenia [12-15]. However, the patient population in which such regimens are safe and effective has yet to be exactly defined [1]. It is generally accepted that response rates are higher in episodes with fever of unknown origin (FUO) than in clinically or microbiologically defined infection (CDI) [16]. In the last 20 years, the rates of FUO have increased while those of CDI and microbiologically defined infections (MDI) have fallen [17]. In episodes with MDI, there has been a pronounced shift in the spectrum of infections since the 1970s away from gram-negative to gram-positive pathogens, primarily coagulase-negative staphylococci and streptococci (particularly viridans species), which are currently blamed for most initial infectious episodes [2].

Fever can be expected to respond rapidly to antibiotic treatment, if neutropenia has lasted less than 1 week and the neutrophil count is $100-1,000 / \mathrm{mm}^{3}$ [18]. In North America, the question of whether it is time to redefine febrile neutropenia and its treatment has been under debate since the mid 1990s [11]. 'Is it time to redefine the therapy of febrile neutropenia? A look at outpatient therapy' was the theme of a special symposium at the 37th Interscience Conference on Antimicrobial Agents and Chemotherapy, which took place in Toronto from 28 September to 1 October 1997. Alternative treatment options might be monotherapy or outpatient treatment in selected low-risk febrile neutropenia. 
At the moment, several questions regarding risk factors of febrile episodes in patients with neutropenia are of particular interest. Talcott et al. [19] showed that febrile neutropenia carried a low risk of complication and a low mortality rate $(2-5 \%)$ in patients with stable underlying disease and no comorbidity. Therefore, there is a current need for prospective studies on infections in cancer patients not limited to antibiotic therapy, but mainly to risk factors of infection, etiology, resistance patterns and outcome. In Europe, however, there is a need for studies to encourage riskadapted treatment, e.g. outpatient-based concepts or monotherapy treatment of febrile neutropenia.

This is the main reason why ESBiC (European Society of Biomodulation and Chemotherapy) is conducting a surveillance study that concentrates more on evaluation of risk factors than on therapeutic outcome of prospective randomized antimicrobial regimens: European Surveillance of Infections in Cancer Patients (ESIC). The present contribution is to determine which patients, if any, are at low risk, and in addition can benefit from firstline treatment with treatment options as monotherapy as well as outpatient treatment.

\section{Aims of the Study}

ESIC is prospectively conducted in patients with treatment of cancer, which is the only entry criterion for patient selection. Furthermore, as many study sites as possible in multiple countries in Europe should be involved. Therefore, ESIC study is a prospective, multicenter European (international) risk factor/outcome identification study. The aim of the study is to identify the type and incidence of risk factors for acquisition of infections and for worst outcome.

European Surveillance of Infections in Cancer

\section{Study Design}

The following data will be documented for stratification:

(a) Malignant disease under antineoplastic therapy, e.g. solid tumor, leukemia, lymphoma or other hematological malignancy.

(b) Treatment regimen (chemotherapy, surgery, multimodal therapy, bone marrow or peripheral stem cell transplantation or others).

(c) Stage of disease (first diagnosis vs. relapse).

If the patient receives antibiotics as prophylaxis/treatment or has acquired an infection, the following data should be documented to identify risk factors:

(1) Exposure to antimicrobial agents (antibiotic treatment/prophylaxis vs. untreated/ not receiving antibiotic/antifungal prophylaxis).

(2) Type of antineoplastic therapy.

(3) Karnofsky Index.

(4) Severity and duration of neutropenia.

(5) Occurrence and duration of febrile episodes.

(6) FUO or documented infection.

(7) Antibiotics used for prophylaxis and/or treatment.

(8) Microorganisms from diagnostic cultures (surveillane cultures excluded).

(9) Results of sensitivity testing (sensitive/ intermediate/resistant) for antibiotics used for prophylaxis/treatment.

(10) Antibiotic-relate adverse drug reaction (ADR).

(11) Clinical outcome according to the response criteria (documented on a case record form):

- in the treatment of infections,

- in the therapy of cancer (for every patient regardless of antibiotics or infection).

Apart from univariate, the multivariate analysis with the logistic regression model will

Chemotherapy 1999;45:237-241 239 
be done in each subgroup concerning possible risk factors for outcome. Additionally, the same analysis will be done for worst outcome (death).

The subgroups may be combined or restricted within groups depending on the hypothesis tested if the sample size permits: e.g. limit the survey to those receiving antineoplastic chemotherapy, or exclude individuals with solid tumors.

\section{Conclusion}

Only a large amount of prospectively collected and centrally validated data with widescale geographic distribution can help us to find answers how to effectively identify and eliminate those risk factors not only associated with infection, but mainly with worst outcome (infection-related mortality). Search for those risk factors, including etiology and resistance to antimicrobials, based on a large amount of data, may help better to organize therapeutic and prophylactic strategies with particular antimicrobial agents.

\section{References}

1 Hughes WT, Armstrong D, Bodey GP, Brown AE, Edwards JE, Feld R, Pizzo P, Rolston KV, Shenep JL, Young LS: 1997 guidelines for the use of antimicrobial agents in neutropenic patients with unexplained fever. Infectious Diseases Society of America. Clin Infect Dis 1997;25: 551-573.

2 Klastersky J: 'Febrile neutropenia'. 20th anniversary of the EORTC Antimicrobial Therapy Cooperative Group. Brussels, December 1993. Support Care Cancer 1994;2:203204.

3 Link H, Maschmeyer G, Meyer P, Hiddemann W, Stille W, Helmerking M, Adam D, for the study group of the Paul-Ehrlich Society for Chemotherapy. Interventional antimicrobial therapy in febrile neutropenic patients. Ann Hematol 1994:69:231-243.

4 Link H, Hiddemann W, Maschmeyer G, Buchheidt D, Glass B, Cornely O, Wilhelm M, Helmerking M, Adam D and the PEG Study Group: Antimicrobial therapy in neutropenic patients with unexplained fever, PEG Study II (abstract LM-47. Abstracts of the 37th Interscience Conference on Antimicrobial Agents and Chemotherapy, Toronto 1997, pp 372-373.
5 Denning $\mathrm{D}$, Meunier $\mathrm{F}$, Cohen $\mathrm{J}$, Marinas A, Krcmery V Jr: Invasive aspergillosis in cancer patients. J Infect 1998;33:332-340.

6 Viscoli C, Martino P, Marinus A, Krcmery V Jr, Meunier F: Survey of candidaemia in cancer patients. Clin Infect Dis 1997;23:1154.

7 Malik LA, Khan WA, Karim M, Aziz Z, Khan MA: Feasibility of outpatient management of fever in cancer patients with low-risk neutropenia: Results of a prospective randomized trial. Am J Med 1995;98: 224-231.

8 Karthaus M, Egerer G, Kullmann KH, Ritter J, Jürgens H: Ceftriaxone in the outpatient treatment of cancer patients with fever and neutropenia. Eur J Clin Microbiol Infect Dis 1998;17:501-504.

9 Karthaus M, Carratala J, Jürgens H, Ganser A: New strategies in the treatment of infectious complications in hematology and oncology: Is there a role for outpatient antibiotic treatment of febrile neutropenia? Chemotherapy 1998;44:427-435.
10 Rubinstein EB, Rolston K, Benjamin RS, Loewy J, Escalante C, Manzullo E, Hughes P, Moreland B, Fen$\operatorname{der}$ A, Kennedy K, et al: Outpatient treatment of febrile episodes in lowrisk neutropenic patients with cancer. Cancer 1993;71:3640-3646.

11 Anaissie EJ, Vadhan-Raj S: Is it time to redefine the management of febrile neutropenia in cancer patients? Am J Med 1995;98:221223.

12 Cometta A, Calandra T, Gaya H, Zinner SH, De Bock R, Del Favero A, Bucaneve G, Crokaert F, Kern WV, Klastersky J, Langenacken I, Micozzi A, Padmos A, Paesmans M, Viscoli C, Glauser MP: Monotherapy with meropenem versus combination therapy with ceftazidime plus amikacin as empiric therapy for fever in granulocytopenic patients with cancer. The International Antimicrobial Therapy Cooperative Group of the European Organization for Research and Treatment of Cancer and the Gruppo Italiano Malattie Ematologiche Maligne dell'Adulto Infection Program. Antimicrob Agents Chemother 1996; 40:1108-1115.

13 Cometta A, Glauser MP: Empiric antibiotic monotherapy with carbapenems in febrile neutropenia: A review. J Chemother 1996;8:375381.

Karthaus et al. 
14 Pizzo PA, Hathorn JW, Hiemenz J, Browne M, Commers J, Cotton D, Gress J, Longo D, Marshall D, McKnight $J$, et al: A randomized trial comparing ceftazidine alone with combination antibiotic therapy in cancer patients with fever and neutropenia. N Engl J Med 1986 315:552-558.

15 Karthaus M, Südhoff T, Wolf HH, Kämpfe D, Egerer G, Ritter J, Peters G, Franke A, Heil G, Kullmann $\mathrm{KH}$, Jürgens H: Ceftriaxone monotherapy in the treatment of low-risk febrile neutropenia. Chemotherapy 1998;44:343-354.
16 Bodey GP: Infection in cancer patients. A continuing association. Am J Med 1986;81:11-26.

17 Klastersky J, Zinner SH, Calandra $\mathrm{T}$, Gaya H, Glauser MP, Meunier F, Rossi M, Schimpff SC, Tattersall M, Viscoli C: Empiric antimicrobial therapy for febrile granulocytopenic cancer patients: lessions from four EORTC trials. Eur J Cancer Clin Oncol 1988;24(suppl 1):35-45.
18 Bodey GP, Buckley M, Sathe YS, Freireich EJ: Quantitative relationships between circulating leukocytes and infection in patients with acute leukemia. Ann Intern Med 1966;64: 328-340.

19 Talcott JA, Siegel RD, Finberg R, Goldman L: Risk assessment in cancer patients with fever and neutropenia: A prospective, two-center validation of a prediction rule. $\mathrm{J}$ Clin Oncol 1992;10:316-322. 